\title{
One-trial aversive conditioning to contextual cues: Effects of time of shock presentation on freezing during conditioning and testing
}

\author{
J. H. ROALD MAES and JO M. H. VOSSEN \\ University of Nijmegen, Nijmegen, The Netherlands
}

\section{(J. M. H. H. van Hest, Sponsor)}

\begin{abstract}
The present experiment examined the course of contextual freezing as a response to the deliv. ery of a single electric footshock. In three groups of rats, the time of shock presentation was manipulated while the total amount of time spent in the shock context was equated among groups. One group received the shock early in the session, a second group was shocked in the middle of the session, and a third group received the shock at the end of the session. An additional control group was included that did not receive a shock. Relative to the early-shock group, the other two shock groups demonstrated a retarded onset of freezing after the shock delivery. During a subsequent nonshock test session, the pattern of freezing in the shock groups was indicative of one-trial temporal conditioning as a result of the previous conditioning session. Taken together, the results suggest that, within the range of the present parameters, manipulations of the time of a single shock presentation result in differences in freezing to contextual cues that are dependent on the presence of temporal cues.
\end{abstract}

Under most conditions, a rat starts to freeze a few seconds after having received a single electric footshock in a distinctive environment. Previous research demonstrated that this freezing reflects a conditioned response to the contextual stimuli that have become associated with shock. For instance, the rat does not freeze when, after shock, it is placed in a distinctively different context (e.g., Fanselow, 1990), and freezing is reinstated when the contextual cues that were present during conditioning are represented (e.g., Fanselow, 1982, 1984).

The incidence of contextual freezing after a single footshock has been demonstated to depend on the amount of experience the animal has had with respect to the training context. The time spent in the context, both before and after the footshock, is important in determining contextual fear. A relatively short time interval (e.g., a few seconds) between placement in the shock context and the occurrence of shock impairs the acquisition of conditioned responding (an effect termed the immediate shock freezing deficit; e.g., Fanselow, 1986). Such an impairment also occurs if the time between placement and shock is relatively long (e.g., more than a few hours; see Balaz, Capra, Kasprow, \& Miller, 1982; Blanchard, Dielman, \& Blanchard, 1968a; Fanselow, 1989). Finally, if an animal spends a long time in the conditioning context after the shock delivery, the freezing response eventually ex-

Correspondence should be addressed to J. H. R. Maes, Department of Comparative and Physiological Psychology, University of Nijmegen, P.O. Box 9104, $6500 \mathrm{HE}$ Nijmegen, The Netherlands (e-mail: u212863@hnykun11.bitnet). tinguishes (e.g., Blanchard, Dielman, \& Blanchard, 1968b).

The purpose of the present experiment was to further examine the involvement of temporal aspects in conditioned contextual responding after a single footshock. Specifically, three groups of rats received a single shock at various times after placement in a context, while the total amount of time spent in the shock context was equated among groups (cf. Fanselow, 1990). Thus, one group received the shock at the beginning of the conditioning session, a second group was shocked in the middle of the session, and a third group received the shock at the end of the session. Finally, a control group was included that did not receive a shock but merely spent the same amount of time in the conditioning box as the other three groups. After the conditioning session, a test session was conducted in which the animals were exposed to the conditioning context without any further events taking place. During both the conditioning/exposure session and the test session, the incidence of freezing was scored and used as an index of fear.

\section{METHOD}

\footnotetext{
Subjects and Apparatus

The subjects were 32 female Wistar rats. Their mean weight at the onset of the experiment was $279 \mathrm{~g}$ (range: $216-351 \mathrm{~g}$ ). The animals were individually housed in Macrolon cages, where they had free access to food and water. They were maintained on a 12:12-h light:dark cycle, and the experiment was conducted during the lights-off portion of the cycle. The subjects had been handled extensively prior to the start of the experiment.

The dimensions of the box that was used for the conditioning session and subsequent test session were $24.5 \times 25 \times 24 \mathrm{~cm}$. The box had clear
} 
Plexiglas front and back walls and aluminum sidewalls. The grid floor consisted of 17 stainless steel rods $(0.3-\mathrm{cm}$ diameter $)$ spaced $1.3 \mathrm{~cm}$ center to center. The grids were connected to a shock generator that provided a 1.0-mA, 2-sec scrambled electric shock. The box was located in a sound-attenuating chamber that had a clear Plexiglas front window. Illumination was provided by two red fluorescent tubes located on the ceiling of the experimental room.

\section{Procedure}

Each rat was assigned to one of four groups $(n=8)$. The animals were matched on the basis of their weight. Each rat in Group BEG ("begin"; the groups' names refer to the moment of shock delivery) was individually placed in the conditioning box, and after $3 \mathrm{~min}$, the shock was delivered. The animals remained in the training box for an additional 21 min. Group MID ("middle") received the shock 12 min after placement in the box and remained there for an additional $12 \mathrm{~min}$. Group END received the shock after $21 \mathrm{~min}$ and was removed from the box $3 \mathrm{~min}$ thereafter. Finally, Group CTRL ("control") was placed in the box for 24 min without any shocks occurring. Note that all animals spent a total of $24 \mathrm{~min}$ in the box. Twenty-four hours after the conditioning session, each animal was returned to the conditioning box and remained there for $24 \mathrm{~min}$ (test session). Throughout the conditioning and test session, each animal was observed every $5 \mathrm{sec}$ (time sampling), and its behavior was scored as either "freezing" or "not freezing." Freezing was defined as the absence of all visible movements except for the following two types of movements: (1) movement that was caused by breathing and (2) a pendulum motion of the head that typically occurs in albino rats when they are emotionally excited (usually when they are fearful). This motion of the head does not occur when rats are active, that is, during locomotion or exploratory activity (see Kolpakov, Borodin, and Barykina, 1977). During the test session, the experimenter was blind with respect to the animals' group assignments.

The freezing data of both the conditioning and test sessions were subjected to a repeated measures analysis of variance (ANOVA). Subsequent simple main-effect analyses were based on the error terms from the overall ANOVA. The degrees of freedom for the error term were computed following the Satterthwaite approximation (Winer, 1971, Chap. 7). To further examine differences between groups, Duncan's new multiple-range post hoc tests were performed. All statistical tests used a rejection criterion set at $p<.05$.

\section{RESULTS}

\section{Conditioning Session}

The left side of Figure 1 shows the groups' incidence of freezing on 3-min periods of the 24-min conditioning session. A 4 (group) $\times 8$ (period) repeated measures ANOVA performed on the freezing data revealed significant main effects of group $[F(3,28)=20.94]$ and pe$\operatorname{riod}[F(7,196)=18.94]$. The group $\times$ period interaction was also reliable $[F(21,196)=7.92]$. The main effect of group was due to the fact that, across periods, Group BEG froze more than did each of the other groups. Analyses of the simple main effect of group at each period revealed a significant group effect at each of periods 2-7 $[F \mathrm{~s}(3,144)>8.57]$. Duncan's tests revealed that at each of Periods 2-4, Group BEG froze more than did each of the other three groups. The latter three groups did not differ from one another. At Period 5, Group BEG still froze more than did each of the other three groups, but additionally, Group MID had started to freeze more than either Group END or Group CTRL (which did not differ). Finally, at Periods 6 and 7, Groups BEG and MID differed from Groups END and CTRL. Group BEG no longer differed from Group MID. At Period 8, no differences between groups could be detected.

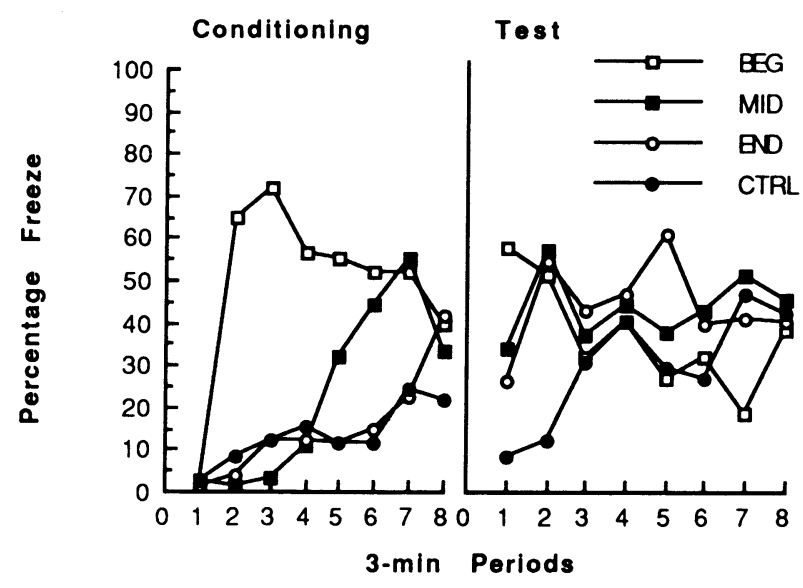

Figure 1. Left: Groups' mean percentage of observations scored as freezing during each of the eight 3-min periods of the conditioning session. Group BEG received an electric shock at the end of Period 1, Group MID was shocked at the end of Period 4, and Group END received the shock at the end of Period 7. Group CTRL did not receive a shock. Right: Groups' mean percentage of samples scored as freezing during the eight 3-min periods of the test session (no shock presented).

To examine the amount of contextual freezing in each of the three shock groups that occurred during the first 3-min period after the shock presentation (i.e., Period 2 for Group BEG, Period 5 for Group MID, and Period 8 for Group END), an ANOVA was performed on the corresponding freezing data with group as the factor. The analysis revealed a significant effect of group $[F(2,21)=$ 4.70]. A Duncan post hoc test revealed that Group BEG froze more than did each of the other two groups. Group MID did not differ from Group END.

Figure 1 suggests that the onset of freezing after shock was somewhat delayed in Group MID, relative to the onset of freezing in Group BEG. Freezing in Group MID reached the highest level during the third 3-min period after shock, whereas freezing in Group BEG was at maximum during the second 3-min period after shock. To further examine the course of freezing during the first three periods after shock delivery in Groups BEG and MID, a separate repeated measures ANOVA was performed with group (2) and period after shock (3) as factors. The analysis failed to detect a significant difference between groups and between periods. However, the group $\times$ period interaction was significant $[F(2,28)=4.02]$. Subsequent simple main effect analyses revealed that at the first two periods after shock, Group BEG froze more than did Group MID $[F \mathrm{~s}(1,26)>4.92]$, whereas during the third 3 -min period after shock, the groups no longer differed.

\section{Test Session}

The right portion of Figure 1 depicts the groups' incidence of freezing during each of the eight 3-min time periods of the 24-min test session performed $24 \mathrm{~h}$ after the conditioning session. The test data were analyzed by means of a 4 (group) $\times 8$ (period) repeated measures ANOVA. The analysis only revealed a significant group $\times$ periods inter- 
action $[F(21,196)=2.97]$. Simple main-effect analyses revealed significant group differences at Periods 1, 2, 5, and $7\left[F_{\mathrm{s}}(3,124)>2.71\right]$. Duncan's tests revealed that at Period 1, Group BEG froze more than did each of the other three groups. Furthermore, during this initial period, Group MID froze more than did Group CTRL. Group END and Group CTRL did not differ. At Period 2, all three shock groups froze more than did the control group, and at Period 5, Group END froze more than did Groups BEG and CTRL, which did not differ. At Period 5, Group END did not differ from Group MID. By the time of Period 7, Group BEG froze less did the other three groups, which did not differ.

The simple effect of period was also analyzed for each group. The analyses revealed a significant effect of period in Groups BEG, END, and CTRL $[F \mathrm{~s}(7,196)>$ 2.17], but not in Group MID $(F=1.13)$. The result regarding Group CTRL reflects the increasing immobility of the rats as the time spent in the box progressed. When rats have spent a considerable amount of time in a particular context without any specific events occurring, it becomes increasingly difficult to distinguish between the behavioral categories "freezing" and "immobile." The null result regarding Group MID is due to the fact that this groups' freezing remained at a relatively constant, intermediate level throughout the entire test session.

\section{DISCUSSION}

The observations during the conditioning session indicate that the freezing response that occurs during the first 3 min after a single, fairly intense footshock is largest when the shock is delivered at the beginning of the session (Group BEG vs. Groups MID and END). However, the analysis of the freezing percentages that were observed subsequent to the initial 3-min period revealed that the initial attenuation merely reflected a delayed onset of Group MID's freezing that eventually came to reach a level that was comparable to that of Group BEG. The same pattern of freezing might also have been observed for Group END if the observations were continued after Period 8.

The data obtained during the test session indicate that the answer to the question as to which treatment during the conditioning session (amount of exposure to the context prior to, or after, a single shock) results in the lowest freezing levels during the test depends on the specific time period that is examined. The pattern of freezing in the shock groups during the test more or less paralleled the course of freezing during the conditioning session. Thus, freezing in Group BEG started early after placement in the shock context and decreased as the session progressed. Instead, Group MID and, especially, Group END reached their highest levels of freezing at some later point in the test session (Periods 2 and 5, respectively). This pattern of results can be interpreted as being due to temporal conditioning during the training phase (for literature on timing behavior, see, e.g., Church, 1989; LaBarbera \& Church, 1974; Libby \& Church, 1975). Notably, in both Groups MID and END, the anticipated time of occurrence of shock during the test session (as demonstrated by the enhanced freezing during Periods 2 and 5 for Groups MID and END, respectively) was two 3-min periods ahead of the actual occurrence of the shock during the conditioning session (Periods 4 and 7 for Groups MID and END, respectively).

Theoretically, there are at least two possible ways in which temporal cues can come to control contextual freezing. One interpretation of the present data is that there are two types of stimuli that each have acquired "simple" excitatory associative strength (e.g., Rescorla \& Wagner, 1972): the training context and temporal cues (i.e., time elapsed between placement and shock; see also Williams, Frame, \& LoLordo,
1992). Only when both types of stimuli are present (or at least stimuli that are somewhat similar), a summation of the two associative strengths occurs and a conditioned response can be observed that significantly differs from the levels of responding in a nonshocked control group. If one of the two sources of excitation is absent (e.g., in case the animals are replaced in their home cages), no freezing is observed (i.e. the rats will not start to freeze in their home cage after the appropriate amount of time has elapsed).

A second possible mode of operation of temporal cues is that they are functioning as stimuli that "set the occasion for" responding or nonresponding to the contextual cues (see the literature on occasion setting; e.g., Holland, 1983, 1985). That is, the temporal cues do not possess any associative strength by themselves but merely act to signal or retrieve a context-footshock association. To put it in other words: the animals only come to remember that the context is linked to the occurrence of a shock in the presence of the appropriate time cues.

To summarize, the results of the present experiment indicate that, even in one-trial aversive conditioning experiments in which, relative to the studies mentioned in the introduction, minor differences are planned between groups with respect to the time of the shock delivery, it is important to examine the course of freezing in conditioning and test sessions. In the present study, such an evaluation revealed as-yet-unreported results: a delayed onset of freezing after a context preexposure of several minutes, and a pattern of freezing during a subsequent test session that reflected one-trial temporal conditioning.

\section{REFERENCES}

Balaz, M. A., Capra, S., Kasprow, W. J., Miller, R. R. (1982). Latent inhibition of the conditioning context: Further evidence of contextual potentiation of retrieval in the absence of appreciable context-US associations. Animal Learning \& Behavior, 10, 242-248.

Blanchard, R. J., Dielman, T. E., \& Blanchard, D. C. (1968a). Postshock crouching: Familiarity with the shock situation. Psychonomic Science, 10, 371-372.

Blanchard, R. J., Dielman, T. E., Blanchard, D. C. (1968b) Prolonged aftereffects of a single foot shock. Psychonomic Science, 10, 327-328.

ChurCh, R. M. (1989). Theories of timing behavior. In S. B. Klein \& R. R. Mowrer (Eds.), Contemporary learning theories: Instrumental conditioning theory and the impact on biological constraints on learning (pp. 41-71). Hillsdale, NJ: Erlbaum.

FANSELOW, M. S. (1982). The postshock activity burst. Animal Learning \& Behavior, 10, 448-454.

FANSELOW, M. S. (1984). Opiate modulation of the active and inactive components of the postshock reaction: Parallels between naloxone pretreatment and shock intensity. Behavioral Neuroscience, 98, 269-277.

FANSELOW, M. S. (1986). Associative vs. topographical accounts of the immediate freezing deficit in rats: Implications for the response selection rules governing species-specific defense reactions. Learning \& Motivation, 17, 16-39.

FANSELOW, M. S. (1989). The adaptive function of conditioned defensive behavior: An ecological approach to Pavlovian stimulus substitution theory. In R. J. Blanchard, P. F. Brain, D. C. Blanchard, \& S. Parmigiani (Eds.), Ethoexperimental approaches to the study of behavior (pp. 151-166). Dordrecht, The Netherlands: Kluwer.

FANSELOW, M. S. (1990). Factors governing one-trial contextual conditioning. Animal Learning \& Behavior, 18, 264-270.

Holland, P. C. (1983). Occasion-setting in Pavlovian feature positive discriminations. In M. L. Commons, R. J. Herrnstein, \& A. R. Wagner (Eds.), Quantitative analyses of behavior: Vol. 4. Discimination processes (pp. 183-206). New York: Ballinger.

HollaND, P. C. (1985). The nature of conditioned inhibition in serial and simultaneous feature negative discriminations. In R. R. Miller \& N. E. Spear (Eds.), Information processing in animals: Conditioned inhibition (pp. 267-297). Hillsdale, NJ: Erlbaum.

Kolpakov, V. G., Borodin, P. M., \& Barykina, N. N. (1977). Catatonic behaviour in the Norway rat. Behaviour, 62, 190-207. 
LaBarbera, J. D., \& ChURCh, R. M. (1974). Magnitude of fear as a function of expected time to an aversive event. Animal Learning \& Behavior, 2, 199-202.

LibBY, M. E., \& СнURCh, R. M. (1975). Fear gradients as a function of the temporal interval between signal and aversive event in the rat. Journal of Comparative \& Physiological Psychology, 88, 911-916.

Rescorla, R. A., \& WAgner, A. R. (1972). A theory of Pavlovian conditioning. Variations in the effectiveness of reinforcement and nonreinforcement. In A. H. Black \& W. F. Prokasy (Eds.), Classical conditioning II: Current research and theory (pp. 64-99). New York: Appleton-Century-Crofts.
Williams, D. A., Frame, K. A., \& LoLordo, V. M. (1992). Discrete signals for the unconditioned stimulus fail to overshadow contextual or temporal conditioning. Journal of Experimental Psychology: Animal Behavior Processes, 18, 41-55.

WINER, B. J. (1971). Statistical principles in experimental design (2nd ed.). New York: McGraw-Hill.

(Manuscript received May 5, 1992.) 